1

Mestre em Administração (2013), Universidade Federal de Pernambuco (UfPe). Professora Assistente do curso de Administração na Universidade Federal Rural do Semi-Árido (UFERSA) . Atualmente cursa doutorado no Programa de Pós-Graduação em Administração da Universidade Federal do Rio Grande do Norte (UFRN).

2

Doutor (2008) e Mestre (2003) em Administração Pública e Governo pela Fundação Getúlio Vargas/sp (FGV-eAESP). Coordenador do Núcleo de Inovação na Gestão Pública, professor do Programa de Pós-graduação em Administração e do Programa de Pós-graduação em Gestão Pública da Universidade Federal do Rio Grande do Norte (UFRN).

\section{DO FATO SOCIAL AO PROBLEMA POLÍTICO ANÁLISE DA PERCEPÇÃO DE PROTETORES E ATORES PÚBLICOS SOBRE OS ANIMAIS DE RUA EM TRÊS MUNICÍPIOS DO RIO GRANDE DO NORTE}

\author{
FROM SOCIAL FACT TO POLITICAL PROBLEM \\ ANALYSIS OF THE PERCEPTION OF PROTECTORS AND \\ PUBLIC ACTORS ABOUT STREET ANIMALS IN THREE \\ MUNICIPALITIES OF RIO GRANDE DO NORTE
}

Danielle de Araújo Bispo Hironobu Sano ${ }^{2}$

RESUMO: O objetivo desse artigo foi responder ao seguinte questionamento: como a situação dos animais de rua se transformou em um problema político em três municípios do Rio Grande do Norte? Como caso de estudo foi considerada a situação de animais domésticos, nomeadamente cães e gatos, em situação de vulnerabilidade social (que estão abandonados nas ruas). Buscou-se estudar tal situação em três municípios do Rio Grande do Norte: Natal, Mossoró e Assu. Realizou-se uma pesquisa qualitativa, utilizando o questionário autoadministrado com perguntas abertas como técnica de coleta de dados. Os dados foram analisados por meio da análise de conteúdo. O fato social vivenciado nos três municípios é idêntico. $O$ problema foi identificado em todos eles como a reprodução descontrolada de animais de rua e a solução apontada para resolver o problema foi a esterilização. Cada município teve sua particularidade na forma de transformar o fato social em problema político e a presença do agenda setters se mostrou mais importante do que as mobilizações sociais para incluir um tema na agenda política.

palavras-chave: Fato Social; Problema Público; Problema Político; Agenda Política; Agenda Setters.

ABSTRACT: The purpose of the article was to answer the following question: How does a situation of street animals become a political problem in three municipalities of Rio Grande do Norte? As a study case, we considered the situation of domestic animals, particularly dogs and cats, in situation of social vulnerability (abandoned on the streets). We sought to study such situation in three municipalities of Rio Grande do Norte: Natal, Mossoró and Assu. A qualitative research was conducted, using the self-administered questionnaire with open questions as a data collection technique. Data were analyzed through content analysis. The social fact experienced in the three municipalities is identical. The problem was identified in all of them as an uncontrolled reproduction of street animals and the solution proposed to solve the problem was sterilization. Each municipality had its particularity in the way of transforming the social fact into political problem and the presence of the agenda setters proved to be more important than social mobilizations to include a theme on the political agenda.

Keywords: Social Fact; Public Problem; Political Problem; Political Agenda; Agenda Setters. 


\section{INTRODUÇÃO}

Este artigo apresenta reflexões sobre como um fato social se transforma em um problema político. De acordo com Kingdon (2006), sabe-se muito pouco sobre como algumas questões entram na agenda do governo, sendo esta uma área imprecisa e pouco estudada. Fuks (2000, p. 80) sugere que no estudo da definição da agenda sejam consideradas duas questões: "1) como surgem novos assuntos públicos e por que alguns (e não outros) ascendem às arenas públicas e ali permanecem (ou não); 2) que atores participam do processo de definição de assuntos públicos".

Para Subirats et al (2010) toda política pública aponta a resolução de um problema público reconhecido como tal na agenda governamental. Representa pois a resposta do sistema político-administrativo a uma situação da realidade social julgada politicamente como inaceitável. Nesta mesma linha de pensamento, Lascoumes e Galès (2012, p. 141) afirmam que "um problema torna-se público a partir do momento em que os atores sociais estimam que algo deve ser feito para mudar uma situação".

Diante disso, este artigo tomou como caso de estudo a situação de animais domésticos, nomeadamente cães e gatos, em situação de vulnerabilidade social (que estão abandonados nas ruas). O conceito de animais domésticos é definido na Portaria no 93 , de julho de 1998, pelo Instituto Brasileiro do Meio Ambiente e dos Recursos Naturais Renováveis (IBAMA) que delimita como animais domésticos aqueles que, dentre outras coisas, apresentam características biológicas e comportamentais em estreita dependência do ser humano.

Assim, de modo ainda exploratório, buscou-se refletir sobre tal situação em três cidades do Rio Grande do Norte: Natal, Mossoró e Assu. A escolha desses municípios se justifica porque no último ano têm-se acompanhado nas redes sociais o trabalho de protetores e o interesse de alguns vereadores dessas cidades na questão do abandono e do controle populacional de cães e gatos.

Antes do desenvolvimento de políticas para cães e gatos, os direitos dos animais de um modo geral já era debatido a nível internacional. Em 1978, em Bruxelas na Bélgica, ativistas da causa animal levaram à Organização das Nações Unidas para a Educação, a Ciência e a Cultura (UNESCO) uma proposta de Declaração Universal dos Direitos dos Animais como intuito de criar parâmetros jurídicos sobre o Direito dos Animais para países membros da Organização das Nações Unidas (SOCIEDADE UNIÃO INTERNACIONAL DOS DIREITOS DOS ANIMAIS, 2018).

Mas, a nível nacional, as preocupações relativas aos animais foram institucionalizadas bem antes da Declaração Universal, em 1924, com o Decreto $n^{0} 16.590$ que regulamentava as casas de diversões públicas proibindo qualquer diversão que causasse sofrimento aos animais. Em 1934, com o Decreto n⿳o 24.645, houve o marco para a história dos direitos dos animais no Brasil, quando o então Presidente Getúlio Vargas proíbe a crueldade e os maus-tratos, estabelecendo penas e multas para 
quem maltratasse um animal e reconhecendo os animais como sujeitos de direito. Contudo, esse decreto foi revogado em 1991 juntamente com outros decretos pelo Presidente Fernando Collor.

A preocupação com a forma como a saúde animal e a saúde humana estão interligadas também situam-se no século $x x$, com a criação dos primeiros canis públicos nas principais capitais do Brasil. Os primeiros centros de zoonoses foram criados na década de 1970 e suas ações estavam voltadas para recolher, vacinar e eutanasiar cães com o objetivo de fazer o controle da raiva. O foco dessas políticas era a prevenção, proteção e promoção da saúde humana (MINISTÉRIO DA SAÚDE, 2016).

Ao longo do tempo, a questão dos animais domésticos passou a ocupar outros espaços além do campo da saúde, como o campo do meio ambiente. Atualmente o regulamento responsável por garantir os direitos dos animais ficou a cargo da Lei n⿳o 9.605 de 1998, conhecida como a Lei dos Crimes Ambientais. Essa lei “dispõe sobre as sanções penais e administrativas derivadas de condutas e atividades lesivas ao meio ambiente, e dá outras providências". Entretanto, apresenta caráter genérico, aplicando-se a diferentes situações onde se pode incluir o caso dos animais domésticos.

É tão recente a compreensão das políticas voltadas para saúde e bem estar animal que apenas recentemente, em 30 de março de 2017, o então Presidente Michel Temer sancionou a Lei Federal no 13.426 que "dispõe sobre a política de controle da natalidade de cães e gatos e dá outras providências". Essa lei que regulamenta o controle de pequenos animais em todo o território nacional é mais um reconhecimento que o problema da superpopulação de cães e gatos vai ao encontro do bem estar do próprio animal.

No Nordeste, alguns municípios começaram recentemente a investir no controle populacional de animais, a exemplo da Prefeitura de Jaboatão dos Guararapes, em Pernambuco, que lançou em 2015 o projeto castramóvel vinculado à Secretaria Executiva de Meio Ambiente e Gestão Urbana (FREIRE, 2015). Em Recife, as políticas de controle populacional são oferecidas pela Secretaria Executiva dos Direitos Animais (SEDA), criada em 2013 (SEDA, 2016).

Entretanto, nos três municípios do Rio Grande do Norte apenas recentemente o tema controle populacional de animais tem permeado o debate público. Em Natal, em junho de 2016, duas unidades castramóveis foram adquiridas pelo município e ficou sob a responsabilidade da Secretaria Municipal de Saúde implementar esta política (NICÁcio, 2016). A Câmara Municipal de Mossoró sancionou em 2017 a primeira lei do município que dispõe sobre o controle populacional de cães e gatos, a Lei $n^{\circ} 3.570$, de 15 de agosto de 2017. Em Assu, o prefeito da atual gestão se reuniu com a oNG sos Animal e agentes de endemias para tratar sobre as demandas dos animais, sobretudo a castração de cães e gatos (Assu TODO DIA, 2017). Ou seja, apenas a partir de 2016 esse problema começa a ganhar maior visibilidade no Rio Grande do Norte. 
Diante desse cenário, rico e atual, o objetivo desse artigo é responder ao seguinte questionamento: como a situação dos animais de rua se transformou em um problema político em três municípios do Rio Grande do Norte? Para isso, fez-se uma pesquisa qualitativa, usando como técnica de coleta dos dados o questionário autoadministrado e para análise a análise de conteúdo. A lente teórica se restringiu principalmente aos trabalhos de Subirats et al (2010) e Lascoumes e Galès (2012), como é apresentado na seção a seguir.

\section{REFERENCIAL TEÓRICO}

\section{ANÁLISE DE POLÍTICAS E ABORDAGEM COGNITIVA}

O processo de análise de uma política pública leva em consideração um conjunto de decisões e ações empreendidas por atores, tanto público como privados, orientadas à solução de um problema público claramente delimitado (SUBIRATS; KNOEPFEL; LARRUE; VARONNE, 2010). Importante esclarecer que atores privados incluem diferentes grupos da sociedade civil e também do setor privado.

De acordo com Muller e Surel (2002), a gênese de uma ação pública pode ser dividida em três processos para fins de análise: problematização dos fenômenos sociais; inscrição formal na agenda e influência das janelas políticas. Para Subirats et al (2010), entender o problema público é o primeiro passo para a análise das demais fases do ciclo de análise da política pública, que engloba: surgimento e percepção dos problemas, incorporação à agenda política, formulação da política, implementação e avaliação.

Portanto, tanto para Muller e Surel (2002) como para Subirats et al (2010) a análise de uma política pública deve se iniciar pela compreensão do fenômeno social que está sendo problematizado, levando-se em consideração a percepção do problema pelos atores.

Este entendimento de problema construído pelos atores é uma visão da abordagem cognitiva que entende as políticas públicas "como matrizes cognitivas e normativas, constituindo sistemas de interpretação do real, no interior dos quais os diferentes atores públicos e privados poderão inscrever sua ação" (MUller; surel, 2002, p. 44). Como construção social, podem existir diferentes visões acerca do problema assim como diferentes soluções (sUBIRATS, 1992).

Para conceituar um problema, Subirats (1992) afirma ser uma situação que deixa os atores insatisfeitos, tratando-se de uma discrepância entre aquilo que é e aquilo que se gostaria que fosse. Em obra mais recente, Subirats et al (2010) explicam que:

Um problema é uma construção coletiva e como uma construção associa-se a percepções, representações, interesses e valores dos atores envolvidos em uma situação. Por isso, é necessário considerá-lo como uma realidade social situada no tempo e espaço, sendo portanto fruto de uma construção histórica (SUBIRATS; KNOEPFEL; LARRUE; VARONNE, 2010, p. 128). 
De acordo com Fuks (2000), a vida política é vista como arena argumentativa, onde os partidos políticos, a mídia, os grupos organizados e o poder público estão em permanente processo de debate. Para Subirats et al (2010), cada ator tem sua margem de manobra em determinada situação. Nenhum campo está livre da intencionalidade do ator pois não existe um campo perfeitamente estruturado, controlado e regulado.

Fora isso, os atores ainda podem apresentar divergências sobre o problema em questão, o que leva a diferentes discursos para abordá-lo, como afirmam Muler e Surel (2002):

A produção de discursos concorrentes sobre um mesmo fenômeno implica por isso mesmo uma competição sobre a qualificação do problema sob um ângulo particular, que implica a seleção das causas consideradas pertinentes, a formulação de uma explicação conforme às "visões de mundo" dos atores envolvidos e, enfim, a elaboração de propostas de resolução do problema (MULLER; SUREL,2002, p. 57).

Considerando portanto a abordagem cognitiva de políticas e a construção dos atores sobre os problemas, a seção a seguir apresenta algumas distinções apresentadas na literatura sobre a problematização de fenômenos sociais.

FATO SOCIAL, PROBLEMA PÚBLICO E PROBLEMA POLÍTICO

Há várias distinções na literatura sobre o que é um fato social ou fenômeno social, problema público ou problema social e problema político. Tudo depende do autor que se está tomando como lente teórica. Para este artigo, optou-se pela distinção entre fato social, problema público e problema político, trabalhada por Lascoumes e Galès (2012), mas considerando também a visão Subirats et al (2010) a fim de enriquecer a discussão.

Lascoumes e Galès (2012) fazem a distinção entre fatos sociais, problema público e problema político. Os fatos sociais são espontâneos, tratando-se de experiências ordinárias, mas que também podem ser representadas por meio de laudos técnicos dos dados. O importante é salientar que para esses autores fatos sociais existem de forma independente de mobilizações sociais.

Já uma situação pode ser vista como um problema público quando por meio de mobilização os atores sociais conseguem inscrevê-la no espaço público, reconhecendo que algo deve ser feito para mudar a situação em que se encontram. Entretanto, nem todo problema público é inscrito na agenda. A inscrição do problema na agenda de ação do Poder Público torna o problema público em problema político (LASCOUMES; GALÈs, 2012).

Em outras palavras, quando a solução almejada para o problema público só pode ser dada pelo poder público tem-se um problema político. Há neste último caso o reconhecimento de que apenas o Estado pode tomar providências, como explicam Lascoumes e Galès (2012): 
Um problema torna-se público a partir do momento em que os atores sociais estimam que algo deve ser feito para mudar uma situação. Ele torna-se político a partir do momento em que a solução almejada só pode ser dada pelo poder público. $\mathrm{O}$ apelo à intervenção do Estado visa, então, a tomada de providências sobre uma questão até então ignorada, ou ainda que a transformação da ação pública em andamento seja questionada por sua insuficiência ou suas orientações [...] (LASCOUMES; GALÈS, 2012, p. 141-142).

Lascoumes e Galès (2012) enfatizam que é necessário dissociar as dimensões fato social, problema público e problema político para análise, mesmo que elas sejam dimensões em interação. Além disso, ressaltam que pode-se passar de um fato social diretamente para um problema político, sem que haja necessariamente a mobilização dos atores da sociedade para que o problema se torne público.

Como exemplo, trazem uma situação ocorrida na França onde especialistas em saúde pública conseguiram que medidas legislativas fossem trabalhadas pelo Estado para sensibilizar a sociedade sobre a nocividade do tabaco. Explicam os autores que a construção do tabagismo como um problema político não aconteceu por meio de reivindicações sociais, mas foi uma construção do aparelho estatal. Em casos como esse, passa-se do fato social para um problema político (LASCOUMES; GALÈS, 2012).

Um pouco diferente da distinção de Lascoumes e Galès (2012), Subirats et al (2010) entendem o problema como problema público a partir do momento em que ele entra na agenda. Ou seja, o que Subirats et al (2010) chamam de problema público, Lascoumes e Galès (2012) chamam de problema político.

Anteriormente a essa entrada na agenda, Subirats et al (2010) falam de problema social, o que Lascoumes e Galès (2012) chamam de problema público. Na linha de pensamento de Subirats et al (2010), Fuks (2000) traz um exemplo esclarecedor sobre quando um problema deve ser considerado social afirmando que uma condição qualquer não constitui um problema social:

[...] uma alegada condição não constitui um problema social enquanto não for enunciada publicamente como tal. Assim, por exemplo, um suposto crescimento em números de abortos não configura um problema social enquanto esta estatística não for veiculada por um grupo que a interprete como 'crime contra a vida' ou, alternativamente, como uma consequência da miséria e da desinformação (FUKS, 2000, p. 81).

Assim, para Subirats et al (2010) e Fuks (2000) os problemas são reconhecidos como sociais desde que haja mobilização dos atores para tal e são reconhecidos como público quando fazem parte da agenda. Diferente de Fuks (2000) que no exemplo anterior sobre o aborto aponta a presença de uma estatística e de um grupo que interprete esta situa- 
ção como um problema social, Lascoumes e Galès (2012) veriam nesta situação um problema público.

Independentemente destas distinções, existem algumas condições que favorecem que um problema social seja transformado em problema público conforme Subirats et al (2010), ou nos dizeres de Lascoumes e Galès (2012) um problema público seja transformado em problema político.

De acordo com Subirats (1992) deve-se considerar as seguintes condições: o tema em questão alcança a proporção de crise e não pode mais ser ignorado; provoca situações emotivas que chamam atenção dos meios de comunicação; adquire importância global; afeta o poder público diretamente; se conecta com tendência ou valores da moda.

Mesmo que um problema social satisfaça todas essas condições, isso não garante que ele entre na agenda. Uma figura é muito importante no trânsito do problema à agenda, os "agenda setters", atores que são influentes na formação da agenda. Os agenda setters podem ser grupos organizados para representar os interesses sociais, partidos políticos, criadores de opinião entre outros (sUBIRATS, 1992).

Para analisar em maior profundidade um problema público, Subirats et al (2010) sugerem quatro dimensões operacionais de análise, conforme O QUADRO 1:

QUADRO 1 - Dimensões operacionais de análise.

\begin{tabular}{|l|l|}
\hline \multicolumn{1}{|c|}{ DIMENSÃO } & \multicolumn{1}{c|}{ DESCRIÇÃO } \\
\hline Intensidade do problema & $\begin{array}{l}\text { Diz respeito ao grau de importância do problema, } \\
\text { tanto a nível individual como coletivo. }\end{array}$ \\
\hline $\begin{array}{l}\text { O perímetro } \\
\text { (ou audiência) } \\
\text { do problema }\end{array}$ & $\begin{array}{l}\text { Por perímetro do problema entende-se a extensão ou } \\
\text { alcance de seus efeitos negativos sobre os diferentes } \\
\text { grupos sociais, a localização geográfica de tais efeitos } \\
\text { negativos e o desenvolvimento do problema no tempo. }\end{array}$ \\
\hline A novidade do problema & $\begin{array}{l}\text { Alguns problemas são novos e outros são crônicos. } \\
\text { Alguns autores sugerem que problemas novos } \\
\text { mobilizam com maior facilidade a opinião pública, } \\
\text { levando atores públicos e privados a intervir. }\end{array}$ \\
\hline A urgência do problema & $\begin{array}{l}\text { A noção de urgência faz referência à noção de crise } \\
\text { conjuntural. }\end{array}$ \\
\hline
\end{tabular}

FONTE: Subirats et al (2010)

Estas quatro dimensões não devem ser consideradas como exaustivas para operacionalizar e comparar os diversos problemas.

\section{AGENDA POLÍTICA}

Kingdon (2006, p. 222) entende a agenda como "a lista de temas ou problemas que são alvo em dado momento de séria atenção, tanto por parte das autoridades governamentais como por pessoas fora do governo, mas estreitamente associadas às autoridades".

Sobre a emergência de questões específicas na agenda, Fuks (2000) afirma que essa ascensão explica-se mais pela dinâmica social e política do que pelo problema e características do problema em si. A 
arena em que os atores se encontram é mais importante para determinar a entrada de um problema na agenda do que o próprio problema.

Um aspecto interessante ressaltado por Kingdon (2006) diz respeito a ordem em que as coisas acontecem. Não necessariamente se identifica o problema para depois se pensar nas soluções, ou seja, "a defesa de soluções frequentemente precede à atenção aos problemas aos quais são associadas" (KINGDON, 2006, p. 240).

Subirats et al (2010) apresentam cinco processos que explicam como um problema pode entrar na agenda política: midiatização, mobilização ou iniciativa externa, oferta política ou competência eleitoral, antecipação interna e ação corporativa silenciosa. Tais processos estão resumidos nO QUADRO 2.

QUADro 2 - Processos de inclusão na agenda política.

\begin{tabular}{|c|c|}
\hline PROCESSOS & DESCRIÇÃO \\
\hline Midiatização & $\begin{array}{l}\text { Nesse processo, a mídia (imprensa escrita, rádio, televisão e } \\
\text { internet) atua na conversão de um tema de interesse social em } \\
\text { uma problemática que chamará atenção dos atores públicos } \\
\text { e partidos políticos. Estes, por sua vez, se (re)apropriam do } \\
\text { tema, fazendo valer suas ideias e programas políticos sobre } \\
\text { o mesmo, promovendo o debate político. }\end{array}$ \\
\hline $\begin{array}{l}\text { Mobilização ou } \\
\text { iniciativa externa }\end{array}$ & $\begin{array}{l}\text { Para esse processo é importante a participação dos atores } \\
\text { organizados para atrair outros atores como a sociedade civil } \\
\text { e políticos para o problema social que entendem ser objeto } \\
\text { de intervenção do poder público. Nesse processo, "parte-se } \\
\text { da hipótese de que a agenda política é estruturada como } \\
\text { uma resposta às demandas sociais claramente articuladas } \\
\text { por grupos de pressão e movimentos sociais" (subIRATs et } \\
\text { al, 2010,p.142). }\end{array}$ \\
\hline $\begin{array}{l}\text { Oferta política } \\
\text { ou competência } \\
\text { eleitoral }\end{array}$ & $\begin{array}{l}\text { Supõe que os partidos políticos e outras organizações } \\
\text { não pretendem apenas reagir às demandas sociais e } \\
\text { articuladas. Nesse processo, os próprios partidos políticos } \\
\text { tomam a iniciativa para resolver o problema em questão. } \\
\text { Portanto, cabe aos partidos a definição de questões públicas } \\
\text { e a agenda política é estabelecida em função dos temas } \\
\text { escolhidos por eles. }\end{array}$ \\
\hline $\begin{array}{l}\text { Antecipação } \\
\text { interna }\end{array}$ & $\begin{array}{l}\text { Nesse modelo, considera-se que os atores administrativos } \\
\text { e as autoridades públicas estão em melhor posição para } \\
\text { identificar desajustes entre as ações estatais atuais e os } \\
\text { problemas sociais ainda não resolvidos. Por conhecer as } \\
\text { políticas vigentes, estariam melhor preparados para sugerir } \\
\text { os temas da agenda política. }\end{array}$ \\
\hline $\begin{array}{l}\text { Ação } \\
\text { corporativista } \\
\text { silenciosa }\end{array}$ & $\begin{array}{l}\text { Quando a agenda política é influenciada por grupos } \\
\text { particulares e que defendem seus interesses a curto prazo, } \\
\text { mantendo, introduzindo ou evitando que algum problema } \\
\text { seja considerado na agenda. }\end{array}$ \\
\hline
\end{tabular}

FONTE: Subirats et al (2010)

Quando um problema entra na agenda (agenda setting), ou seja, o problema é identificado, definido e construído, tem-se segundo Muller e Surel (2002), as condições para a gênese da ação pública. 


\section{METODOLOGIA}

Esta pesquisa considerou a percepção dos atores sociais sobre como um fato social vem a se tornar um problema político. Portanto, assumiu-se que a realidade é uma construção social, baseada nas vivências dos atores, o que enquadra esta pesquisa no paradigma construtivista, conforme tratado por Lincoln e Guba (2006). Para este tipo de paradigma, a abordagem que melhor se adéqua é a qualitativa, pois o pesquisador interpreta o fenômeno por meio dos significados que as pessoas apresentam sobre ele (DENZIN; LINCOLN, 2006; SILVERMAN, 2009).

A técnica de coleta de dados adotada foi o questionário autoadministrado com perguntas abertas. Segundo Marconi e Lakatos (2013), o questionário é um instrumento que deve ser respondido sem a presença do pesquisador. Para esta pesquisa, tratou-se de um questionário autoadministrado por envio, ou seja, oferecido ao participante por e-mail (SAMPIERI; COLLADO; LUCIO, 2013).

Esta técnica foi a selecionada devido a algumas peculiaridades da pesquisa. Era necessário poupar tempo e viagens, ao mesmo tempo em que se considerasse os três municípios selecionados: Natal, Assu e Mossoró. As perguntas abertas proporcionaram maior liberdade nas respostas atendendo o que a pesquisa qualitativa exige sobre o ponto de vista de cada ator social. Além disso, os respondentes tiveram um prazo de cinco dias para devolver o questionário respondido, apresentando portanto flexibilidade de horário para responder.

O questionário foi elaborado de modo que o tempo estimado para respondê-lo fosse no máximo de 30 minutos. Dez questões foram distribuídas em três blocos: fato social, problema público e problema político. Foram enviados via e-mail 14 questionários para 6 protetores e 8 atores públicos em setembro de 2017. Dez pessoas responderam: 5 protetores e 5 atores públicos, conforme QUADro 3. Será mantido o anonimato dos respondentes.

QUADRO 3 - Caracterização dos respondentes.

\begin{tabular}{|c|c|c|c|c|c|}
\hline $\mathrm{N}^{\circ}$ & TIPO DE ATOR & CIDADE & PROFISSÃO & GRUPO/ONG & CODINOME \\
\hline 1 & Ator público & Natal & Assessor parlamentar & 一 & Público $1 \mathrm{~N}$ \\
\hline 2 & Ator público & Natal & Servidor Público & - & Público 2N \\
\hline 3 & Ator público & Mossoró & $\begin{array}{l}\text { Farmacêutico-bioquímico, } \\
\text { advogado, ex- vereador }\end{array}$ & 一 & Público 1M \\
\hline 4 & Ator público & Mossoró & Servidor Público & - & Público $2 \mathrm{M}$ \\
\hline 5 & Ator público & Assu & Servidor Público & 一 & Público A \\
\hline 6 & Protetor & Natal & Arquiteta e Urbanista & ONG Patamada Natal & Protetor $\mathrm{N}$ \\
\hline 7 & Protetor & Mossoró & Professora & $\begin{array}{c}\text { Movimento Mossoroense } \\
\text { de Proteção Animal }\end{array}$ & Protetor $1 \mathrm{M}$ \\
\hline 8 & Protetor & Mossoró & $\begin{array}{l}\text { Graduanda em Medicina } \\
\text { Veterinária }\end{array}$ & Adote Mossoró & Protetor $2 \mathrm{M}$ \\
\hline 9 & Protetor & Assu & $\begin{array}{l}\text { Professor e Técnico em } \\
\text { Saúde Bucal }\end{array}$ & sos Animal & Protetor $1 \mathrm{~A}$ \\
\hline 10 & Protetor & Assu & $\begin{array}{l}\text { Graduanda em Medicina } \\
\text { Veterinária }\end{array}$ & sos Animal & Protetor 2A \\
\hline
\end{tabular}

FONTE: Dados da pesquisa, 2017. 
Para selecionar os respondentes, fez-se uso de alguns critérios. O critério adotado para os protetores foi ser atuante na causa animal, participando de algum grupo de proteção animal e/ou Organização Não Governamental (ONG). Já para os atores públicos, o critério adotado foi que tivesse estabelecido contato por meio de reuniões e/ou audiência com algum grupo de proteção animal e/ou onG, pois isso mostraria algum envolvimento com a questão animal em sua cidade.

No que diz respeito à técnica de análise, optou-se pela análise de conteúdo. De acordo com Flick (2009) uma característica essencial desse tipo de análise é o uso de categorias, normalmente obtidas a partir de modelos teóricos. Assim, foram definidas como categorias teóricas apriorísticas: fato social, problema público, problema político, intensidade do problema, a audiência do problema, a novidade do problema, a urgência do problema e processos de inclusão na agenda política.

\section{DESCRIÇÃO DOS DADOS}

\section{FATO SOCIAL}

Quando questionados sobre a situação dos cães e gatos de rua dos seus municípios, os atores públicos e protetores ressaltaram palavras similares para descrevê-la: abandono, descaso, superpopulação, ausência de políticas públicas, problema ambiental e problema de saúde pública. No QUADRO 4, é possível obervar alguns trechos onde a situação é relatada pelos respondentes de cada município:

QUADRO 4 - Situação dos animais de rua por município.

\begin{tabular}{|l|l|}
\hline MUNICÍPIO & \multicolumn{1}{c|}{ TRECHOS } \\
\hline \multirow{5}{*}{ Natal } & $\begin{array}{l}\text { Infelizmente por falta de políticas públicas voltadas à causa animal } \\
\text { com reflexos na saúde pública, os animais vivem em eterno abandono } \\
\text { e sem os mínimos cuidados básicos necessários e como consequência, } \\
\text { ampliam-se as colônias especialmente de felinos, com doenças de } \\
\text { todos os tipos, sequer existe um censo desses bichinhos. Só para ter } \\
\text { ideia do alcance, somente o ano passado foram eutanasiados 1.717 } \\
\text { cães no ccz, por estarem com leishmaniose e pior, estão todos sendo } \\
\text { enterrados no aterro sanitário, desse modo, comprometendo o meio } \\
\text { ambiente (Público 2N, o5/og/2017, grifos nossos). }\end{array}$ \\
\hline \multirow{5}{*}{ Mossoró } & $\begin{array}{l}\text { A situação dos animais nas ruas da nossa cidade, Mossoró-RN, é de } \\
\text { total abandono. Tal fato se deve ao descaso do poder público e de } \\
\text { grande parte da sociedade civil que é indiferente à situação, o que } \\
\text { representa um sério problema, visto que, além de todo o sofrimento } \\
\text { pelo qual esses cães e gatos passam em decorrência de doenças, } \\
\text { fome, sede, frio, medo, maus tratos, etc, existe um risco eminente } \\
\text { de acidentes e zoonoses, doenças transmissíveis entre animais e } \\
\text { humanos" (Protetor 1M, o4/og/2017, grifos nossos). }\end{array}$ \\
\hline $\begin{array}{l}\text { Muitos animais abandonados, doentes e famintos nas ruas. É um } \\
\text { problema tanto de saúde pública como social. Descaso público, } \\
\text { já que a cidade até então não executa nenhum projeto em prol } \\
\text { da redução de natalidade desses animais, os efeitos são vários, } \\
\text { disseminação de doenças, como a leishmaniose, inclusive, há casos } \\
\text { humanos em Assu, e o sofrimento de mais e mais animais (Protetor } \\
\text { 2A, o5/og/2017, grifos nossos). }\end{array}$ \\
\hline Assu
\end{tabular}

FONTE: Dados da pesquisa, 2017. 
Todos os respondentes acreditam que para mudar o atual quadro dos seus municípios, deve-se investir em uma política preventiva por meio do controle populacional de cães e gatos. Tal responsabilidade caberia às prefeituras, segundo eles, como pode-se extrair dos trechos a seguir nO QUADRO 5 .

QUADRO 5 - Responsabilização das prefeituras.

\begin{tabular}{|c|c|}
\hline MUNICÍPIO & TRECHOS \\
\hline \multirow{3}{*}{ Natal } & $\begin{array}{l}\text { Devemos mudar essa situação o quanto antes, e devemos partir } \\
\text { do principio de tentar controlar a natalidade dessa população [...]. } \\
\text { A responsabilização desta tarefa deveria caber principalmente a } 2 \\
\text { secretarias, de saúde e do meio ambiente (Público } 1 \mathrm{~N} \text {, 02/o9/2017, } \\
\text { grifos nossos). }\end{array}$ \\
\hline & $\begin{array}{l}\text { A prefeitura precisa urgentemente preparar um plano a médio e } \\
\text { longo prazo e que consiga dá conta dos cuidados e saúde pública } \\
\text { preventiva (Público } 2 \mathrm{~N}, 05 / 09 / 2017 \text {, grifos nossos). }\end{array}$ \\
\hline & $\begin{array}{l}{[\ldots] \text { a responsabilidade por esses animais deveria ser da prefeitura }} \\
\text { municipal [...] Os castramóveis, veículos com atendimento móvel } \\
\text { de castração felina e canina deveriam estar nas ruas, ajudando a } \\
\text { castrar os animais das protetoras, dos abrigos e ongs [...] (Protetor N, } \\
\text { 04/og/2017, grifos nossos). }\end{array}$ \\
\hline \multirow{3}{*}{ Mossoró } & $\begin{array}{l}\text { Percebemos o Poder Público lento na percepção do problema e } \\
\text { ainda mais lento na tomada de decisões (Público 1M, 04/o9/2017, } \\
\text { grifos nossos). }\end{array}$ \\
\hline & $\begin{array}{l}\text { Até o momento, o poder público municipal nada tem feito para } \\
\text { resolver o problema. A única medida efetuada pelo ccz - Centro de } \\
\text { Controle de Zoonoses [...] é uma campanha anual de vacinação contra } \\
\text { a raiva (Protetor } 1 \mathrm{M}, 04 / 09 / 2017 \text {, grifos nossos). }\end{array}$ \\
\hline & $\begin{array}{l}\text { O poder público de fato, pouco se importa com essa situação. Os que } \\
\text { ainda tentam se mobilizar de alguma forma, pouco conseguem [...] } \\
\text { (Protetor } 2 \mathrm{M}, 06 / 09 / 2017 \text {, grifos nossos). }\end{array}$ \\
\hline Assu & $\begin{array}{l}\text { "Acredito que o controle de natalidade dos animais de rua seja a } \\
\text { única saída para o abandono destes nas ruas e acredito que isso é de } \\
\text { responsabilidade dos governos municipais" (Protetor 1A, 02/09/2017, } \\
\text { grifos nossos). }\end{array}$ \\
\hline
\end{tabular}

FONTE: Dados da pesquisa, 2017.

Um respondente de Mossoró, Protetor 1M, responsabiliza também a sociedade civil ao dizer que "a sociedade civil [...] precisa se mobilizar e cobrar de seus governantes que sejam adotadas medidas de políticas públicas para os animais" (Protetor 1M, 04/09/2017). Já em Assu, o respondente Público A explica que uma forma de reduzir a quantidade de animais de rua é punir quem os abandona. Já para Protetor $1 \mathrm{~A}$ caberia à prefeitura fazer o controle populacional dos animais de rua por meio da esterilização, como mostra o QUADRO 7.

Enquanto os municípios permanecem sem políticas públicas de controle populacional para os animais de rua, são os protetores e as ongs que desenvolvem ações no intuito de remediar o problema. Segundo os respondentes dos três municípios, essas ações incluem o resgate de animais de rua, assistência veterinária, esterilização para evitar crias indesejadas e campanhas de adoção.

Sobre essas ações, Protetor 1M explica que ela apenas ameniza a situação de alguns animais de rua e que os mesmos cumprem "uma 
função que o Município deveria assumir" e que "a demanda da cidade é enorme e acaba que enquanto essas pessoas e/ou grupos conseguem salvar alguns, tem que fechar os olhos para o sofrimento de muitos outros" (Protetor 1M, 04/09/2017). O respondente Público 1N acredita que essas ações conseguem mudar a vida de alguns animais, mas nas suas palavras "estamos apenas maquiando a situação". Neste mesmo sentido, o respondente "Protetor N", afirma que "as soluções encontradas pelos protetores da cidade são paliativas".

\section{PROBLEMA PÚBLICO}

Apenas o município de Mossoró contou com mobilizações sociais para fazer a situação dos animais de rua ser reconhecida como um problema público. Tem-se um caso típico de fato social que se transforma em problema público antes de ser visto como um problema político.

A situação dos animais de rua veio a se tornar um problema público quando protetores buscaram se unir em 2015 por meio de mobilização social pelas redes sociais e em ato público nas ruas do centro de Mossoró para sensibilizar a sociedade civil e cobrar medidas ao Poder Público. Uma vez ao ano, desde 2015, os protetores e simpatizantes fazem uma caminhada simbólica pedindo políticas públicas para os animais. Os protetores explicaram que:

Existe um grupo, o Movimento Mossoroense de Proteção Animal, que foi formado por protetoras há 3 anos com o objetivo de alertar a sociedade civil acerca do problema, bem como, de convocar outros protetores e simpatizantes da causa a se unirem para pressionar o poder público, fazendo com que assumam as suas responsabilidades (Protetor 1M, 04/o9/2017).

O Movimento Mossoroense de Proteção Animal surgiu com o intuito de reunir todos os grupos de proteção da cidade e dessa forma, reunir forças e lutar por políticas públicas em prol deles. Seja com caminhadas, com cartazes informativos, com informações direcionados às redes sociais, na câmara de vereadores com projetos de lei que almejam castrações (Protetor 2M, 06/og/2017).

Houve, portanto, um planejamento dos protetores da cidade para trabalhar o assunto como problema público. Para isso, o apoio da mídia foi essencial, embora ocorra mais nas épocas próximas à caminhada de proteção animal, como explica Protetor 1M:

Com a página do Movimento Mossoroense de Proteção Animal, que tem um cunho mais educativo e politizado, conseguiu desde o seu primeiro ano chamar a atenção da mídia local, principalmente, em períodos de pré caminhada, sendo convidado para entrevistas em jornais impressos, rádio e TVs a nível municipal e estadual (Protetor 1M, 04/09/2017). 
Os atores públicos só começaram a se interessar pelo problema depois que os protetores foram às ruas.

PROBLEMA POLÍTICO

NATAL

Quando questionados sobre como o tema havia chegado à Câmara Municipal de Natal para fazer parte da agenda política, ficou evidente a importância de uma figura pública que é vereador do município.

Esse problema chegou ao debate na Câmara através de uma solicitação de criação de leis para proibir o tráfego de carroças em Natal, com isso foi criado uma Frente Parlamentar em Defesa dos Direitos dos Animais para debater toda a problemática relacionada aos animais da nossa cidade. [...] Atualmente a figura de destaque é o vereador [...], que tem trabalhado com as protetoras e a sociedade num todo para tentar conseguir a efetivação das leis e principalmente políticas públicas relacionadas aos animais [...] (Público 1N, 02/09/2017).

[...] esse tema chegou à câmara municipal de Natal, por ocasião da minha eleição. [...] senti que o parlamento estava órfão desse assunto e já tratei de me inserir e depois, presidir a Frente Parlamentar em Defesa dos Direitos dos Animais (Público 2N, 05/09/2017).

Em Natal, portanto, passa-se do fato social ao problema político, pois o assunto entrou na agenda política do município mais devido a Público $2 \mathrm{~N}$, que é vereador do município, do que por mobilizações sociais. Sobre as mobilizações, Público $1 \mathrm{~N}$ explica que são organizadas por Público 2N, como se lê no trecho a seguir:

Aqui existe um Vereador [...] que tem conseguido mobilizar as protetoras e com isso chamar a atenção das autoridades. Exemplo disso, são os atos públicos para comemorar a incompetência da prefeitura em operacionalizar os veículos de castramóveis. Esses atos têm causado uma repercussão muito negativa para a gestão, mas ainda, não conseguimos fazer com que esse constrangimento se torne numa política efetiva e efetivada. O que tem se conseguido é expor o problema e cobrar uma solução (Público 1N, 02/09/2017).

Observa-se que as mobilizações referidas acima não são para o tema entrar na agenda política, pois o mesmo já encontra-se em discussão. As mobilizações acontecem para implementar a política de castramóveis, sendo organizadas pelo próprio vereador, uma vez que o mesmo já havia adquirido os castramóveis por meio de emendas parlamentares.

A mídia tem desempenhado um fraco papel para que a situação dos animais de rua seja visto como um problema público, como revelado pelos respondentes: 
Pouco se observa esse problema na mídia, o pouco espaço que é tratado sobre o tema, é abordado sempre por jornalistas que são sensíveis à causa dos animais (Público 1N, 02/09/2017).

Infelizmente a mídia quando explora a questão animal, tem muito mais o objetivo comercial do que educacional. Não mostra a importância da mobilização social como instrumento de conquistar (Público 2N, 05/09/2017).

A internet ainda é o melhor meio de divulgação, é rápido, gratuito e se alcança um grande número de pessoas em pouco tempo. Os outros canais de divulgação em massa como TV e rádio ainda não abriram de vez suas portas para o nosso trabalho (Protetor N, 04/09/2017).

Em relação à legislação voltada para cães e gatos no município de Natal, os atores públicos afirmam que o município possui um código de defesa dos animais, uma lei de controle populacional, uma lei que pune com multas os maus tratos e uma lei que autoriza o transporte em ônibus de pets até 1okg.

Para respondente Público $1 \mathrm{~N}$, "A secretaria de meio ambiente tem desenvolvido um trabalho ímpar no que compete à verificação in loco da situação dos maus tratos aos animais e atuado com sanções administrativas e muitas vezes até apreensão dos animais" (Público 1N, 02/09/2017). Já o respondente Público 2N ressalta as campanhas de vacinação antirrábicas como única ação que tem sido implementada. E divergindo dos demais, Protetor $\mathrm{N}$ afirma: "Não há políticas públicas vigentes. Os animais estão abandonados a sua sorte" (Protetor N, 04/09/2017).

Apesar dessas diferentes posturas dos respondentes, essas leis revelam como os atores públicos têm compreendido que cabe à prefeitura a responsabilidade pelos animais do município.

MOSSORÓ

Em Mossoró, o problema saiu do âmbito público para o político quando o assunto dos animais de rua chegou à Prefeitura Municipal de Mossoró por meio de convocação do Ministério Público para que a Secretaria de Saúde do Município trabalhasse juntamente com o Hospital Veterinário da Universidade Federal Rural do Semi-Árido. O Objetivo era promover a esterilização de animais tirados da rua por protetores e ampliar para sociedade civil, mas essa tentativa não deu certo, como se extrai do trecho a seguir:

O Movimento tentou, junto ao Ministério Público, formalizar uma parceria entre o hospital veterinário da ufersa e a Prefeitura Municipal para desenvolver um projeto de controle populacional através da castração de animais. Mas mesmo após várias reuniões no próprio MP, com o promotor do meio ambiente, representantes do hospital veterinário, da prefeitura e de protetores independentes, assim como, protetores de onGs e dos 
grupos de proteção da cidade, a prefeitura não cumpriu com a parte que lhe cabia no acordo e o projeto nunca saiu do papel (Protetor 1M, 04/o9/2017).

Diante deste impasse, o Movimento contou com apoio de um vereador da cidade, o respondente Público 1M. Sobre isso, explica: "Fomos escolhidos pelas entidades protetoras para tentar sensibilizar o poder público da real necessidade de uma ação mais enérgica sobre essa problemática" (Público 1M, 04/og/2017). Público 1M diz ter sido procurado pelos grupos de proteção animal, mas Protetora $1 \mathrm{M}$ afirma que $\mathrm{o}$ Movimento que foi procurado, como é possível observar:

A causa animal chegou a Câmara Municipal de Mossoró alguns meses após a primeira caminhada realizada pelo grupo do Movimento pelas ruas da cidade. Com a visibilidade e o espaço que o grupo ganhou nas mídias da cidade e com uma parcela cada vez maior da sociedade cobrando do poder público em redes sociais, o então vereador [...] procurou o grupo, montou e apresentou o projeto na Câmara Municipal. Além disso, o mesmo também solicitou uma audiência pública na Câmara, onde estavam presentes todos os grupos e ongs de proteção animal da cidade, bem como vários protetores independentes (Protetor 1M, 04/09/2017).

Quando questionados se o poder público de Mossoró possui alguma legislação voltada para cães e gatos, os atores públicos e um protetor afirmaram que existe uma lei de controle populacional e incentivo à adoção, aprovada em agosto de 2017. Apesar do município de Mossoró possuir essa lei, a política ainda não foi implementada por falta de verba, segundo Protetor 1M: "A luta agora é para conseguir que os vereadores apresentem e aprovem uma emenda coletiva que destine recursos para que a lei seja colocada em prática [...]" (Protetor 1M, 04/09/2017).

Observa-se em Mossoró que a situação dos animais de rua consegue ganhar status de problema político, mas nada além disso.

ASSU

Em Assu, de acordo com os protetores, o poder público colocou na agenda política a situação dos animais da cidade devido à pressão social e da ong sos Animal, como explica Protetor 2A: "Através da sos ANIMAL, que buscou incluir no plano de governo dos então candidatos a prefeito ações voltadas para a questão animal, obtendo êxito com um candidato, que hoje é o prefeito e está disposto a iniciar as castrações de animais de rua" (Protetor 2A, 05/09/2017). Além do prefeito, Público A, que é vereador do município, também levou o assunto para a Câmara Municipal, como explica Protetor 1A:

Ele conheceu o nosso trabalho pelas redes sociais e se solidarizou e nos propôs essa ação legislativa. O prefeito municipal [...] também tem se mostrado sensível à 
causa e já nos recebeu em três audiências para tratar da problemática que envolve os animais de rua de Assu/RN (Protetor 1A, 02/09/2017).

O respondente Público A, vereador referido anteriormente, explica que o trabalho realizado de modo voluntário pelas ongs da cidade o sensibilizou a reconhecer a necessidade de políticas públicas para os animais: "Isso me sensibilizou ao ponto de comprar algumas brigas, ou seja, apresentar alguns projetos que viessem também dar sustentação e apoio a esse trabalho que eles vinham prestando ao nosso município de uma forma voluntária" (Público A, 06/09/17).

A ong participa do Conselho Municipal de Saúde e recentemente fez um projeto de controle populacional dos animais de rua que foi apresentado ao prefeito do município.

A sos Animal de Assu [...] tem assento no Conselho Municipal de Saúde da cidade. Sempre estamos pautando as questões afetas aos Animais de rua. Apresentamos um Projeto de Castração Pública à prefeitura de Assu que já foi aprovado pela Procuradoria do Município e está em processo de execução (Protetor 1A, 02/09/2017).

Na percepção dos protetores de Assu esta é uma situação que preocupa toda a sociedade. Já Público A explica que essa preocupação com os animais de rua é de uma minoria. As passagens abaixo resumem suas percepções:

Acredito que preocupa toda a sociedade. Já participamos de várias entrevistas em programas de rádio na cidade de Assu e, em todos eles a população interage repassando a ideia de que o cuidado aos Animais de rua vem, a cada dia, se tornando uma exigência da população para que se transforme numa ação efetiva do serviço público (Protetor 1A, 02/09/2017).

Ao meu ver, isso representa a preocupação de uma minoria. [...] infelizmente a nossa cultura ainda é muito arcaica nesse sentido quando se acha que se tem que cuidar primeiro da saúde dos humanos e depois cuidar da saúde dos animais. [...] (Público A, 06/og/17).

Sobre o papel da mídia para dar visibilidade a situação dos animais de rua, os protetores explicam que a mídia tem cada vez mais se interessado no problema e já participaram de várias programas locais falando sobre o assunto, como resume um deles: "Os protetores de animais de Assu/Rn tem tido total apoio da imprensa falada, escrita e televisiva. Esse assunto está sempre em pauta e já participamos de vários programas para tratar do assunto" (Protetor 1A, 02/09/2017). Entretanto, para Público A, o tema é mais divulgado pelas pessoas por meio das redes sociais e grupos de WhatsApp.

O Município ainda não possui uma legislação sobre controle populacional, mas está sendo realizado um convênio público-privado pra 
realizar as castrações. Também está em construção o projeto de lei do vereador Público a que visa punir maus tratos e abandono:

Nós estamos dando entrada na casa com um projeto de lei que visa punir, ou seja, multar quem [...] abandonar ou maltratar animais. Também é uma iniciativa nossa a questão das castrações, um convênio público-privado que vai ser executado em nosso município (Público A, o6/o9/17).

Sendo assim, em Assu a situação dos animais de rua faz parte da agenda política, embora ainda não tenha políticas de controle populacional implementadas.

\section{ANÁLISE DOS DADOS}

Nos três municípios, os protetores vivem uma situação de crise porque não dão conta da demanda de animais de rua, sendo o apoio do poder público de cada município essencial. O que parece ser a causa geradora de todos os demais problemas na percepção dos respondentes é a superpopulação de animais de rua.

Essa delimitação do problema é importante segundo Subirats et al (2010) para orientar a solução. Neste caso, a solução apontada tanto pelos atores públicos como pelos protetores é a esterilização desses animais, pois diminuiria o número de animais de rua, e consequentemente o abandono, as doenças e as zoonoses, além de garantir um meio ambiente mais equilibrado. Como um problema socialmente construído, conforme explicado por Muller e Surel (2002), onde os atores podem ter diferentes sistemas de interpretação, foi possível observar que os respondentes buscam defini-lo principalmente como questão de saúde pública.

Cada município teve sua particularidade na forma de tornar o problema político. Tanto em Natal quanto em Assu, o fato social se transformou em problema político. Foi explicado por Lascoumes e Galès (2012) que em alguns casos, o fato social se transforma em problema político sem necessariamente passar por mobilizações da sociedade civil. Em Mossoró, observa-se a inscrição do fenômeno no espaço público por meio de mobilizações dos protetores, onGs, grupos de proteção animal e simpatizantes. De todo modo, nos três municípios, a solução almejada é dependente do poder público, como explica Lascoumes e Galès (2012).

A entrada na agenda política é facilitado pela figura dos "agenda setters" nos três municípios. Em Natal, Público 2N é presidente da Frente Parlamentar dos Direitos dos Animais assim como garantiu a compra dos castramóveis. Em Mossoró, Público 1M apresentou projeto de lei sobre controle populacional que em agosto de 2017 foi promulgado. Em Assu, Público 1A trabalha junto com a sos Animal e está preparando um projeto de lei sobre maus tratos e abandono. Desse modo, os atores públicos têm sido uma importante porta de entrada para o tema ser debatido nas câmaras municipais, corroborando com Subirats (1992) 
quando o autor explica que a figura do agenda setters é muito importante na formação da agenda, mas isso não garante a implementação das políticas, como explicam Lascoumes e Galès (2012). Levando-se em conta as quatro dimensões operacionais de análise, conforme Subirats et al (2010), é possível resumir os dados no QUADRO 6.

QUADRo 6 - Dimensões operacionais de análise.

\begin{tabular}{|l|l|}
\hline \multicolumn{1}{|c|}{ DIMENSÃO } & \multicolumn{1}{|c|}{ DESCRIçÃo } \\
\hline $\begin{array}{l}\text { Intensidade do } \\
\text { problema }\end{array}$ & $\begin{array}{l}\text { A situação dos animais de rua é vista como um } \\
\text { problema maior para os protetores que lidam } \\
\text { diariamente com os animais. A sociedade de um modo } \\
\text { geral parece não perceber a gravidade do problema. } \\
\text { Alguns vereadores começam a perceber o problema } \\
\text { como um caso de saúde pública e que portanto merece } \\
\text { atenção do município. }\end{array}$ \\
\hline $\begin{array}{l}\text { O perímetro (ou } \\
\text { audiência) do problema }\end{array}$ & $\begin{array}{l}\text { Os respondentes afirmam ser um problema de saúde } \\
\text { pública para expressar a audiência do problema } \\
\text { estendendo-o a toda sociedade. }\end{array}$ \\
\hline A novidade do \\
problema & $\begin{array}{l}\text { A superpopulação dos animais de rua apenas foi } \\
\text { construída como um problema político recentemente } \\
\text { no estado do Rio Grande do Norte. Observam-se as } \\
\text { conquistas recentes: os castramóveis adquiridos no ano } \\
\text { de } 2016 \text { em Natal; a lei de reprodução de cães e gatos } \\
\text { em 2017 em Mossoró; o convênio público-privado em } \\
\text { 2017 em Assu. }\end{array}$ \\
\hline A urgência do problema \\
$\begin{array}{l}\text { Não representa crise conjuntural em nenhum dos três } \\
\text { municípios,a ponto de afetar diretamente a maior parte } \\
\text { da sociedade. }\end{array}$ \\
\hline
\end{tabular}

FONTE: Dados da pesquisa, 2017.

Em relação aos processos de inclusão na agenda política, apesar dos três municípios possuírem a midiatização em comum, em cada um deles houve um processo principal, conforme o QUADRO 7.

QUADRO 7 - Processo de inclusão na agenda política por município.

\begin{tabular}{|l|c|l|}
\hline MUNICÍPIO & PROCESSO & \multicolumn{1}{c|}{ DESCRIÇÃo } \\
\hline Natal & $\begin{array}{c}\text { Oferta política } \\
\text { ou competência } \\
\text { eleitoral }\end{array}$ & $\begin{array}{l}\text { O vereador Público IN tomou a iniciativa de criar } \\
\text { a Frente Parlamentar dos Direitos dos Animais, } \\
\text { assim como adquirir os castramóveis, definindo } \\
\text { as questões que deveriam ser implementadas. }\end{array}$ \\
\hline Mossoró & $\begin{array}{c}\text { Mobilização } \\
\text { ou iniciativa } \\
\text { externa }\end{array}$ & $\begin{array}{l}\text { Nesse caso, vê-se a organização dos atores por } \\
\text { meio do Movimento Mossoroense de Proteção } \\
\text { Animal para chamar atenção da sociedade e do } \\
\text { poder público para o problema. }\end{array}$ \\
\hline Assu & Midiatização & $\begin{array}{l}\text { Houve principalmente a apropriação do tema } \\
\text { pelo atual prefeito durante sua candidatura, o } \\
\text { que facilitou sua entrada na agenda quando o } \\
\text { mesmo se tornou prefeito. }\end{array}$ \\
\hline
\end{tabular}

FONTE: Dados da pesquisa, 2017.

Por fim, apesar do fato social vivenciado em cada município ser praticamente o mesmo, cada um deles encontrou uma forma de entrar na agenda política. 


\section{CONSIDERAÇÕES FINAIS}

$\mathrm{O}$ questionamento que esse artigo se propôs a responder foi: como a situação dos animais de rua se transformou em um problema político em três municípios do Rio Grande do Norte?

Ao tomar como caso de estudo a situação dos animais de rua de Natal, Mossoró e Assu foi possível tecer algumas reflexões. Esta situação pode ser considerada praticamente a mesma, ou seja, o fato social vivenciado nos três municípios é idêntico. $O$ problema foi identificado em todos eles como a reprodução descontrolada de animais de rua e a solução apontada para resolver o problema foi a esterilização.

A superpopulação desses animais é vista por diferentes ângulos, como o abandono, o descaso, o meio ambiente e a saúde pública. Porém, todos eles usaram como argumento principal para tornar o tema de interesse político o fato de ser um problema de saúde pública que coloca em risco a vida de outras pessoas e de outros animais, por meio de zoonoses. É importante salientar que a superpopulação não foi vista em nenhum momento como um problema que poderia ser resolvido por meio da educação da sociedade para não abandonar os animais nas ruas.

O que diferencia os três municípios são os atores e a forma como os mesmos encontraram de transformar o fato social em problema político. Dos três municípios, Natal é o único município que conseguiu implementar a esterilização como política pública em setembro de 2017, uma vez que o vereador Público $2 \mathrm{~N}$ assumiu a causa animal como interesse prioritário do seu mandado. Isso facilitou que o fato social se transformasse em problema político, sem necessariamente passar por mobilizações sociais para entrar na agenda política. De modo semelhante à Natal, a oNG sos Animal conseguiu transformar o fato social em problema político devido à abertura ao tema pelo novo prefeito de Assu e da simpatia do vereador Público A.

Em Mossoró, as mobilizações surtiram efeito e fizeram com que o fato social se convertesse em problema público e posteriormente problema político, por meio da promulgação da lei de controle populacional, mas o fim do mandado do vereador Público 1м dificultou que a mesma fosse implementada.

O que pode-se concluir desses três casos é que a presença do agenda setters é mais importante do que as mobilizações sociais para incluir um tema na agenda. A transformação de um fato social em problema político acontece com maior rapidez quando algum ator público abraça o problema para fazer parte das ações do seu mandato. Isso sugere que o poder para mudar a situação não está nas mãos dos grupos organizados, mas dos atores públicos que podem se articular para fazer valer seus interesses.

Os grupos organizados podem até conseguir transformar o fato social em problema público, mas deste para o político é facilitado com a figura do agenda setters. E mesmo quando o fato social se transforma primeiramente em problema político, ainda assim no caso dos animais 
de rua, é preciso trabalhá-lo como problema público para legitimar o problema também para a sociedade.

Por fim, esse trabalho apresentou algumas limitações metodológicas. Devido à técnica de coleta de dados ter sido o questionário, observou-se que algumas respostas apresentaram caráter genérico. Por outro lado, como contribuição pode-se elencar a comparação entre os três municípios, o que se constitui um exercício empírico para compreender como os fatos sociais se tornam problemas políticos. No mais, outras pesquisas podem buscar responder como um fato social se transforma em problema político, analisando outros contextos ou mesmo continuar explorando a situação dos animais de rua.

\section{REFERÊNCIAS}

BRASIL. Decreto no 16.590 , de 10 de Setembro de 1924. Aprova o regulamento das casas de diversões publicas. Disponível em: <http://www2.camara.leg.br/legin/fed/ decret/1920-1929/decreto-16590-10-setembro-1924-509350republicacao-90848-pe.html>. Acesso em: 03 mar 2017.

Decreto no 24.645, de 10 de Julho de 1934. Estabelece medidas de proteção aos animais. Disponível em: < http://www2. camara.leg.br/legin/fed/decret/1930-1939/decreto-24645-10-julho1934-516837-publicacaooriginal-1-pe.html>. Acesso em: 03 mar 2017.

Lei $\mathbf{n}^{\mathbf{0}}$ 13.426, de 30 de março de 2017. Dispõe sobre a política de controle da natalidade de cães e gatos e dá outras providências. Disponível em: < http://www.planalto.gov.br/ccivil_03/_ ato2015-2018/2017/Lei/L13426.htm>. Acesso em: 31 mar 2017.

Lei $\mathrm{n}^{0}$ 9.605, de 12 de fevereiro de 1998. Dispõe sobre as sanções penais e administrativas derivadas de condutas e atividades lesivas ao meio ambiente, e dá outras providências. Disponível em: < http://www.planalto.gov. br/ccivil_03/leis/l9605.htm>. Acesso em: 03 mar 2017.

. Ministério da Saúde. Secretaria de Vigilância em Saúde. Departamento de Vigilância das Doenças Transmissíveis. Manual de vigilância, prevenção e controle de zoonoses: normas técnicas e operacionais. Brasília: Ministério da Saúde, 2016.

CÂMARA MUNICIPAL DE MOSSORÓ. Lei n⿳o $\mathbf{3 5 7 0}$, de 15 de agosto de 2017. Dispõe sobre o controle de reprodução de cães e gatos no município de Mossoró e dá outras providências. Disponível em: < http://www.prefeiturademossoro. com.br/jom/jom420a.pdf $>$. Acesso em: 04 set 2017.

DENZIN, Norman k; LINCOLN, Yvonna S. O planejamento da pesquisa qualitativa: teorias e abordagens. 2 ed. Porto alegre: Artmed, 2006.

FREIRE, Juliana. Castramóvel completa um mês e abre espaço para adoção. Diário de Pernambuco, Jaboatão dos Guararapes, 15 jul 2015. Disponível em: < http://www.diariodepernambuco.com.br/ app/46,53/2015/07/15/interna_pecao,586538/castramovel-completa-ummes-e-abre-espaco-para-adocao.shtml $>$. Acesso em: o8 dez 2016. 
FREIRE, Juliana. Castramóvel completa um mês e abre espaço para adoção. Diário de Pernambuco, Jaboatão dos Guararapes, 15 jul 2015. Disponível em: < http://www.diariodepernambuco.com.br/ app/46,53/2015/o7/15/interna_pecao,586538/castramovel-completa-ummes-e-abre-espaco-para-adocao.shtml>. Acesso em: o8 dez 2016.

FUKS, Mario. Definição de agenda, debate público e problemas sociais: uma perspectiva argumentativa da dinâmica do conflito social. BIB, Rio de Janeiro, n. ${ }^{\circ} 49,1 .^{\circ}$ semestre de 2000, pp. 79-94.

IBAMA. Portaria no 93, de 07 de julho 1998. Disponível em: < http://ibama.gov.br/phocadownload/cites/legislacao/1998_ibama_ portaria_93_1998_importacao_exportacao_fauna_silvestre_ lista_fauna_domestica.pdf $>$. Acesso em: 23 mai 2017.

KINGDON, J. Como chega a hora de uma idéia?. In: Saravia, E.; Ferrarezi, E. (Org.). Políticas Públicas. Coletânea - Volume 1. Brasília: ENAP, 2006, pp. 219-224.

LASCOUMES, Pierre; GALÈSS, Patrick le. Sociologia da ação pública. Maceió: EDUFAL, 2012.

LINCOLN, Yvonna S; GUBA, Egon. G.. Controvérsias paradigmáticas, contradições e confluências emergentes. In: DENZIN, Norman K.; LINCOLN, Yvonna S. (orgs.). $O$ planejamento da pesquisa qualitativa: teorias e abordagens. Porto Alegre: ArtMed, 2006. p. 191-215.

MARCONI, M. DE A.; LAKATOS, E M. Técnicas de pesquisa: planejamento e execução de pesquisas, amostragens e técnicas de pesquisa, elaboração, análise e interpretação de dados. $7^{\mathrm{a}}$ Ed. São Paulo: Atlas, 2013.

MULLER, Pierre; Surel, Yves. A análise das políticas públicas. Pelotas: 2002, Educat.

NICÁCIO, Rafael. Natal ganha 'castramóvel' que fará atendimento gratuito. Portal Nio, Natal, 26 jul 2016. Disponível em: < http://oportalnio.com.br/natal-ganha-castramovel-que-faraatendimento-gratuito-50376/>. Acesso em: 30 jul 2017.

PREFEITO de Assu discutiu políticas para animais de rua com Agentes de Endemias e ONG. Assu todo dia. Assu, 7 ago 2017. Disponível em: < https://assutododia.blogspot.com.br/2017/o8/ prefeito-de-assu-discutiu-politicas.html . Acesso em: 04 set 2017.

SAMPIERI, Roberto Hernández; CALLADO, Carlos Fernández; LUCIO, María del Pilar Baptista. Metodologia de pesquisa. $5^{\underline{a}}$ ed. Porto Alegro: Penso, 2013.

SECRETARIA EXECUTIVA DOS DIREITOS DOS ANIMAIS (SEDA). Castração gratuita de cães e gatos. Prefeitura do Recife, 27 jun 2016. Disponível em: < http://www2.recife.pe.gov.br/27/06/2016/ castracao-gratuita-de-caes-e-gatos>. Acesso em: o8 dez 2016.

Castração gratuita de cães e gatos. Prefeitura do Recife, 27 jun 2016. Disponível em: < http://www2.recife.pe.gov.br/27/06/2016/ castracao-gratuita-de-caes-e-gatos $>$. Acesso em: o8 dez 2016. 
SILVERMAN, David. Interpretação de dados qualitativos: métodos para análise de entrevistas, textos e interações. 3 ed. Porto Alegre: Artmed, 2009.

SOCIEDADE UNIÃO INTERNACIONAL DOS DIREITOS DOS ANIMAIS (SUIPA). Declaração Universal dos Direitos dos Animais. Disponível em: <http://www.suipa.org.br/index. asp?pg=leis.asp\&id_esfera=1>. Acesso em: 05 fev 2018.

SUBIRATS, Joan. Análisis de políticas públicas y eficacia de la Administración. Madrid: Ministério para las Administraciones Publicas, 1992.

SUBIRATS, Joan; KNOEPFEL, Peter; LARRUE, Corinne; VARONNE, Frederic. Análisis y gestión de políticas públicas. Espanha: Planeta, 2010. 